\title{
A study of Vitamin-D and nutritional status in recurrent respiratory tract infections in children 1-5 years of age
}

\author{
Ruhi A. ${ }^{1}$, Ananth T. ${ }^{2}$ \\ ${ }^{1}$ Dr. Apsia Ruhi, Resident, Department of Endocrinology, Gandhi Medical College, Secunderabad, Telangana, India. ${ }^{2}$ Dr. \\ Tudumu Ananth, Associate Professor, Department of Paediatrics, Bhaskar Medical College, Yenkapally, Moinabad, \\ Ranga Reddy District, Telangana, India.
}

Corresponding Author: Dr. Tudumu Ananth, Associate Professor, Department of Paediatrics, Bhaskar Medical College, Yenkapally, Moinabad, Ranga Reddy District, Telangana, India. E-mail: drananthbmc@gmail.com

\begin{abstract}
Objective: To assess and explore the association of Vitamin D deficiency with recurrent respiratory tract infections in children less than 5 years. Design: This was a prospective non-randomized two group design study. Duration: One year and four months, i.e. July 2015 to October 2016. Setting: Department of Pediatrics, Bhaskar Medical College, Telangana, India. Participants: 90 children, all aged less than 5 years, attending the Department of Pediatrics, Bhaskar Medical College. Methods: Out of total 90 cases, 50 children with recurrent respiratory tract Infections (RRTI) were taken as Group I, while 40 children without recurrent respiratory tract Infections were taken as Group II. After thorough clinical examination, Serum Vitamin D levels were estimated by Radio Immune Assay (RIA) technique. Statistical analysis was done using appropriate software. Results: Serum Vitamin D levels ranged from 20 to $140 \mathrm{nmol} / 1$. It was depicted that $86 \%$ of children with recurrent respiratory tract infections had Vitamin D deficiency. Vitamin D deficiency and number of respiratory tract infections are more in male children. The mean Vitamin D level in Group I (RRTI) was low i.e. $41.7 \mathrm{nmol} / \mathrm{I}$ compared to $64.6 \mathrm{nmol} / 1$ in Group 11 (no RRTI). Vitamin D deficiency and number of respiratory tract infections were more in the 37-48 months age group. Vitamin D levels were low in children who were exclusively breast fed for 6 months (47\%). Vitamin D levels were low in children who had poor exposure to sunlight (79\%). Conclusion: There was a significant association between Vitamin D levels and recurrent respiratory tract infections. Education regarding the importance and timing of sun exposure is necessary. Routine Vitamin D supplementation is recommended.
\end{abstract}

Key words: Vitamin D Deficiency, Respiratory Tract Infections, Children, Recurrent

\section{Introduction}

The role of diet in the development of rickets was determined by Edward Mellany between1918-1920 [1]. In 1921, ELMER Mc Collum identified an anti-rachitic substance found in certainfats could prevent rickets [2].

Because the newly discovered substance was the fourth Vitamin identified, it was called D Vitamin. Vitamin D deficiency is considered to be the mostcommon nutritional deficiency. Vitamin $D$ is a group of fat soluble pro-hormones, the twomajor forms of which are vitamin D2 (or ergocalciferol) and vitamin D3 (orcholecalciferol). Vitamin D is crucial for musculoskeletal development. The main function of vitamin D in the body is to regulate calcium and phosphorous

Manuscript received: $5^{\text {th }}$ April 2019

Reviewed: $16^{\text {th }}$ April 2019

Author Corrected: $21^{\text {st }}$ April 2019

Accepted for Publication: $26^{\text {th }}$ April 2019 homeostasis, aprocess essential for bone mineralization [3]. Vitamin D also required for the contraction of muscles, nerve conduction and functioning of all cells of the body [4]. In India sub clinical vitamin D deficiency is wide spread in all age groups. Vitamin D can be obtained from sunlight exposure and diet. Since few foods contain vitamin D, sunlight exposure is the primary determinant of vitamin D status in humans [5]. The amount of Vitamin D from sun differs with skin colour, season and pollution [6].

Dietary intakes of both calcium and vitamin D are verylow in majority of population except in high socioeconomic groups [7]. The concentration of Vitamin D must be interpreted in the context of season, as higher concentrations areobserved during summer months [8]. 


\section{Original Research Article}

People living at high altitudes are more prone to seasonal Vitamin D deficiency as in winter, this is possibly because winter time sunlight does not promote conversion of Vitamin D precursors in skin [9]. In recent years, a wide variety ofconditions such as autoimmune diseases, cardiovascular diseases, cancers, type 2 diabetes have also been shown to be associated with vitamin D deficiency [10].

Vitamin D is found naturally in very few foods. Foods containing Vitamin D include some fatty fish (mackerel, salmon, sardines), and fish liver oils, egg yolk. Other sources of Vitamin D include fortified foods particularly dairy products and some cereals.

Lack of sunlight exposure, outdoor activity in sun, poor vitamin D intake are associated factors for its deficiency [11]. Milk from themothers whose diet is sufficient and properly balanced will supply all the necessary nutrients except fluoride and vitamin D [12].

Concentration of vitamin $\mathrm{D}$ is $0.5-101 \mathrm{U} / 100 \mathrm{~m} 1$ of breast milk. Pediatric respiratory tract infections are one of the most common reasons for physician visits and hospitalization, and are associated with significant morbidity and mortality. Respiratory infections are common and frequent diseases and present one of the major complaints in children. Recurrent throat problems in children are common and have animpact on the family. Time off school or parental time off work was significantly associated with parental worry and disruption.

This study is intended to evaluate the possible association of vitamin D deficiency and nutritional status with recurrent respiratory infectionsin children aged less than five years. The aim of the study is to study the association ofvitamin D deficiency with recurrent respiratory tract infections in children less than 5 years.

To assess Vitamin D levels and nutritional status in recurrent respiratory tract infections, explore the association between Vitamin D deficiency and recurrent respiratory tract infections and to study prevalence of Vitamin D in children less than 5 years.

\section{Materials and Methods}

Place of Study: Department of Pediatrics, Bhaskar Medical College, Yenkapally, Moinabad, Raga Reddy District, Telangana, India.

Type of Study: This was a prospective non-randomized two group design study.

Sample Collection: All patients aged less than 5 years with and without recurrent respiratory tract infections attending the outpatient department or admitted as inpatient in the Department of Pediatrics, Bhaskar Medical College who fulfill the inclusion criteria were included in the study. About $3 \mathrm{ml}$ of blood was collected and sent for serum $25(\mathrm{OH})$ vitamin D analysis.

Sampling Methods: This study is designed to detect a difference of at least $40 \%$ in the prevalence of vitamin deficiency between cases and controls. In order to detect this difference at 5\% level of significance an $90 \%$ power of the test the minimum sample required is 36 per group.

In order to reach a set of 72 evaluate children (cases and controls) we targeted 90 patients after factoring anticipated dropouts and patients who will not consent to participate. Serum $25(\mathrm{OH})$ D levels were measured by Radio Immune Assay (RIA).

\section{Inclusion Criteria}

1. Children between 1 month to 5 years of age

2. Children with symptoms of recurrent respiratory tract infections.

\section{Exclusion Criteria}

1. Children less than 1 month of age and greater than 5 years of age.

2. Children with congenital heart disease.

3. Recipients of massive dose of Vitamin D supplementation within last 4 weeks.

Statistical Methods: Statistical analysis was done using appropriate software.

\section{Results}

A total of 90 children were considered for study during the study period. Out of total 90 cases, 50 children with recurrent respiratory tract infections were taken as group I, while 40 children without recurrent respiratory tract infections (RRTI) were taken as Group II.

In Group I (RRTI), 86\% (43) children had vitamin D deficiency whereas, in Group II (no RRTI), $35 \%$ ( 14) had vitamin $\mathrm{D}$ deficiency having vitamin D deficiency increases the odds of RRTI by 11 times (the risk in increased by 11 times). 
Table-1: Vitamin D levels Vs RRTI

\begin{tabular}{|c|c|c|c|c|c|}
\hline $\begin{array}{c}\text { Vitamin D } \\
\text { levels(ng/ml) }\end{array}$ & $\begin{array}{c}\text { Group I (RRTI) } \\
\mathbf{n}=\mathbf{5 0}\end{array}$ & $\begin{array}{c}\text { Group II } \\
\text { (no RRTI) n=40 }\end{array}$ & Total & $\begin{array}{c}\text { OR } \\
(95 \% \mathrm{CI})\end{array}$ & P Value \\
\hline Deficiency $<20$ & $43(86 \%)$ & $14(35 \%)$ & $57(63 \%)$ & \multirow{3}{*}{$\begin{array}{c}11.41 \\
(3.69-37.17)^{* *}\end{array}$} & \multirow{3}{*}{$<0.001 * *$} \\
\hline Normal $=/>20$ & $7(14 \%)$ & $26(65 \%)$ & $33(37 \%)$ & & \\
\hline Total & $50(100 \%)$ & $40(100 \%)$ & $90(100 \%)$ & & \\
\hline
\end{tabular}

OR: odds ratio, CI: confidence interval, **: highly significant, *: not significant

Table-2: Vitamin D mean (SD) among studied groups

\begin{tabular}{|c|c|c|c|c|}
\hline $\begin{array}{c}\text { Vitamin D } \\
\mathbf{n m o l} / \mathbf{I}\end{array}$ & Group I (RRTI) $\mathbf{n}=\mathbf{5 0}$ & Group II (no RRTI) $\mathbf{n = 4 0}$ & T & P-Value \\
\hline Mean (SD) & $41.7(15.1)$ & $64.6(34.2)$ & 4.25 & 0.0001 \\
Range & $20-100$ & $20-140$ & & \\
\hline
\end{tabular}

P-value $<0.01$ : Highly Significant

In addition to the above analysis, mean values of vitamin D were compared between the two groups. The mean value of vitamin D for Group I (RRTI) was 41.7 compared to Group II 64.6 (no RRTI). There is a highly significant positive correlation between vitamin D and RRTI group.

Table-3: Exclusive breast feeding V/s Vitamin D among the studied Groups

\begin{tabular}{|l|c|c|c|c|c|c|}
\hline \multirow{2}{*}{$\begin{array}{l}\text { Exclusive breast } \\
\text { feeding for 6 } \\
\text { months }\end{array}$} & \multicolumn{2}{|c|}{ Group I (RRTI) (n=50) } & \multicolumn{2}{c|}{ Group II (no RRTI) (n=40) } \\
\cline { 2 - 7 } & $\begin{array}{c}\text { Vitamin D } \\
\text { Deficient }\end{array}$ & $\begin{array}{c}\text { Vitamin D } \\
\text { Normal }\end{array}$ & Total & $\begin{array}{c}\text { Vitamin D } \\
\text { Deficient }\end{array}$ & $\begin{array}{c}\text { Vitamin D } \\
\text { Normal }\end{array}$ & Total \\
\hline Given & $20(47 \%)$ & $4(57 \%)$ & $24(48 \%)$ & $1(7 \%)$ & $21(81 \%)$ & $22(52.5 \%)$ \\
\hline Not given & $23(53 \%)$ & $3(43 \%)$ & $26(52 \%)$ & $13(93 \%)$ & $5(19 \%)$ & $18(47.5 \%)$ \\
\hline Total & $43(100 \%)$ & $7(100 \%)$ & $50(100 \%)$ & $14(100 \%)$ & $26(100 \%)$ & $40(100 \%)$ \\
\hline OR & \multicolumn{3}{|c|}{$\begin{array}{c}0.65 \\
(0.1-4.4)^{*}\end{array}$} \\
Df & \multicolumn{3}{|c|}{$0.91^{* \#}$} & & 0.02 \\
\hline P value & \multicolumn{3}{|c|}{} & & \multicolumn{3}{c|}{$<0.004-0.19)^{* *}$} \\
\hline
\end{tabular}

OR: odds ratio, CI: confidence interval, ${ }^{* *}$ : highly significant, ${ }^{*}$ : not significant, ${ }^{\#}$ : Yates correction

In Group I (RRTI), Vitamin D was deficient in 53\% of children who had not received exclusive breast feeding for 6 months whereas in Group II(no RRTI) 93\% were Vitamin D deficient in non-exclusive breast feeding

Table-4: H/o Sunlight Exposure v/s Vitamin D among the studied Groups

\begin{tabular}{|c|c|c|c|c|c|c|}
\hline \multirow{2}{*}{$\begin{array}{l}\text { H/o Sunlight } \\
\text { Exposure } \\
\text { (between } 10 \\
\text { am to } 3 \mathrm{pm} \text { ) }\end{array}$} & \multicolumn{3}{|c|}{ Group I (RRTI) $(n=50)$} & \multicolumn{3}{|c|}{ Group II (no RRTI) $(\mathrm{n}=40)$} \\
\hline & $\begin{array}{c}\text { Vitamin D } \\
\text { Deficient }\end{array}$ & $\begin{array}{c}\text { Vitamin D } \\
\text { Normal }\end{array}$ & Total & $\begin{array}{c}\text { Vitamin D } \\
\text { Deficient }\end{array}$ & $\begin{array}{c}\text { Vitamin D } \\
\text { Normal }\end{array}$ & Total \\
\hline Yes & $9(21 \%)$ & $2(29 \%)$ & $11(22 \%)$ & $1(7 \%)$ & $21(81 \%)$ & $22(55 \%)$ \\
\hline No & $34(79 \%)$ & $5(71 \%)$ & $39(78 \%)$ & $13(93 \%)$ & $5(19 \%)$ & $18(45 \%)$ \\
\hline Total & $43(100 \%)$ & $7(100 \%)$ & $50(100 \%)$ & $14(100 \%)$ & $26(100 \%)$ & $40(100 \%)$ \\
\hline $\begin{array}{l}\text { OR } \\
(95 \% \mathrm{CI})\end{array}$ & \multicolumn{3}{|c|}{$\begin{array}{c}0.66 \\
(0.1-8.1)^{*}\end{array}$} & \multicolumn{3}{|c|}{$\begin{array}{c}0.02 \\
(0.0004-0.2)^{* *}\end{array}$} \\
\hline $\mathrm{P}$ value & \multicolumn{3}{|c|}{$0.96^{* \#}$} & \multicolumn{3}{|c|}{$<0.001^{* * \#}$} \\
\hline
\end{tabular}

OR: odds ratio, CI: confidence interval, ${ }^{* *}$ : highly significant, ${ }^{*}$ : not significant, ${ }^{*}$ : Yates Correction

79\% of Group I (RRTI) 93\% of Group II (no RRTI) who were not exposed to sunlight had vitamin D deficiency. 
Original Research Article

Table-5: Number of patients with deficient and normal vitamin D levels in different RRTIs

\begin{tabular}{|l|c|c|c|}
\hline \multirow{2}{*}{\multicolumn{1}{c|}{ Diagnosis }} & \multicolumn{2}{c|}{ Group I (RRTI) (n=50) } \\
\cline { 2 - 4 } & Vitamin D Deficient & $\begin{array}{c}\text { Vitamin D } \\
\text { Normal }\end{array}$ & Total \\
\hline Bronchopheumonia & 19 & 2 & 21 \\
\hline HRAD (Hyperreactive airway disease) & 10 & 2 & 12 \\
\hline Bilateral maxillary sinusitis & 3 & 0 & 1 \\
\hline Left maxillary sinusitis & 0 & 1 & 3 \\
\hline WALRI (Wheeze associated LRTI) & 3 & 0 & 1 \\
\hline Right paracardiac Consolidation & 1 & 0 & 2 \\
\hline Right lobar Consolidation & 2 & 0 & 1 \\
\hline Left lobar Consolidation & 1 & 0 & 5 \\
\hline Bronchiolitis & 4 & 1 & 1 \\
\hline Tracheobronchitis & 1 & 0 & $\mathbf{5 0}$ \\
\hline Total & $\mathbf{4 4}$ & $\mathbf{6}$ & \\
\hline
\end{tabular}

Among 50 cases in group 1 with RRTI 44 children (88\%) are vitamin deficient.

Among 50 cases in group 1 with RRTI 44 children (12\%) are vitamin D deficient and most of the bronchopneumonia and HRAD patients had the deficiency.

\section{Discussion}

The association between Vitamin D levels and susceptibility to recurrent respiratory tract infections was studied in children less than 5 years. Serum 25hydroxy Vitamin D levels were measured in children with recurrent respiratory tract infections as well as in healthy, similar age group without history of respiratory tract infections.

In our study, there were insignificant differences between Group I (RRTI) and Group II (no RRTI) regarding age, gender and site of residence to explain the low levels of Vitamin D in the group 1 (RRTI). Similarly study done by Albannaet.al, also showed no significant difference between cases and controls regarding socio demographic variables. In a another similar study done by Wayse et.a1[13] with 80 cases and 70 controls there was no significant difference between cases and controls with age distribution ( $\mathrm{P}$ value $=0.09$ ) similarly the study didn't find any significance in the proportion of children in cases and controls pertaining to other socio demographic variables.

The main finding of our study was that serum 25hydroxy Vitamin D concentrations in the Group I (RRTI) was significantly lower than those in the Group II (no RRTI). In Group 1 (RRTI), 86\% had Vitamin D deficiency where as in Group II (no RRTI) 35\% which is comparable to Wayseet.al [13] (80\% and 31\%), Roth et.al [14] (84\% and 60\%), and little higher percentage of deficiency was found in Karatekin [15] i.e. $92 \%$ in group I and $80 \%$ in group II.

Mean Vitamin D Levels- Mean value of Vitamin D was low 41.7 in Group I (RRT1) compared to 64.6 in Group II (no RRTI) which is comparable with Wayse et.al [13] (22.8 and 38.4), Roth [14] et.al 48 (29.1 and 39.1) and Karatekins [15] (22.8 and 40.8). There is a significant correlation was found between Vitamin D deficiency and RRTI group $(\mathrm{P}$-value $=<0.001)$

Sex Distribution- In our study, there were no significant differences in the Vitamin D deficiency between males and females $(\mathrm{P}$-value $=0.91)$ similar to Nighathaideret.a1 [16] study.

Age Distribution- In our study, there were no significant differences with Vitamin D deficiency with respiratory tract infections between the age groups 1month-5 years. In contrast to our study WAYSE [13] et.al 47 showed that serum 25-hydroxy Vitamin D levels increase significantly with age $(\mathrm{P}$-value $<0.001)$. However, Nighathaider et al [16] in their study of 137 children with respiratory tract infections showed that highest incidence of Vitamin D deficiency was found in age group of 2-12 months (79.8\%).

Exclusive Breast Feeding- Vitamin D deficiency was seen $(47 \%)$ in exclusively breastfed infants for 6 months. 
Original Research Article

No significant association was found between exclusive breast feeding and Vitamin D deficiency in recurrent respiratory tract infections $(\mathrm{F}$-value $=0.91)$. However, in another study done by Nighathaideret. a1 [16], Vitamin D deficiency was more common in breast fed infants i.e. $85 \%$.

Sun Exposure- 79\% of Vitamin D deficiency was seen in children who were not exposed to sunlight and only in $21 \%$ cases Vitamin D was deficient even with adequate sun exposure (P-value $=0.96)$ which is comparable to a study done by Nighathaider et.al [16], which showed Vitamin D deficiency is more common in children who were not exposed to sunlight (98.3\%).

\section{Conclusions}

This study showed that $86 \%$ of children with recurrent respiratory tract infections had Vitamin D deficiency. Vitamin D deficiency and number of respiratory tract infections are more in male children than female children. The mean Vitamin D level in Group I (RRTI) was low $41.7 \mathrm{nmol} / \mathrm{I}$ compared to $64.6 \mathrm{nmol} / 1$ in Group 11 (no RRTI). Vitamin D deficiency and number of respiratory tract infections are more in the 37-48 months age group followed by 13-24 months age. Vitamin D levels were low in children who were exclusively breast fed for 6 months (47\%).

Vitamin D levels were low in children who had poor exposure to sunlight (79\%). There is a need for prospective randomized trials in this field to establish cause effect relation between Vitamin D and RRTI. Education regarding the importance and timing of sun exposure should be done ( $1 / 2$ hour a day for 5-6 day/week bet. $10 \mathrm{am}$ to $3 \mathrm{pm}$ ). As most of the children are deficient in serum Vitamin D levels, routine Vitamin D supplementation may be recommended from birth onwards.

Funding: Nil, Conflict of interest: None initiated, Perission from IRB: Yes

\section{References}

1.Mellanby E. Nutrition Classics. The Lancet 1:407-12, 1919. An experimental investigation of rickets. Edward Mellanby. Nutr Rev. 1976 Nov; 34(11):338-40.

2. McCollum EV, Simmonds N, Becker JE, Shipley PG. Studies on experimental rickets. XXI. An experimental demonstration of the existence of a vitamin which promotes calcium deposition. J. Biol. Chem. 1922;53:293-312.
3. Arya V, Bhambri R, Godbole MM, Mithal A. Vitamin D status and its relationship with bone mineral density in healthy Asian Indians. Osteoporos Int. 2004 Jan;15(1):56-61. Epub 2003 Sep 12.

4. Diazlopez B,CannataAndiaJB.Supplementation of Vitamin D and calcium;advantages and risks.Nephrol dial transplant.2006;2:2375-7.

5. Harinarayan CV, Ramalakshmi $\mathrm{T}$, Prasad UV, Sudhakar D, Srinivasarao PV, Sarma KV, Kumar EG. High prevalence of low dietary calcium, high phytate consumption, and vitamin $\mathrm{D}$ deficiency in healthy south Indians.Am J ClinNutr. 2007 Apr;85(4):1062-7.

6.Cannenll JJ, Hollis BW, ZasloffM, Heaney RP. Diagnosis and treatment of vitamin D deficiency. Expertopin pharmacotherapy.2008;9;107-18

7. Holick MF. Sunlight and vitamin D for bone health and prevention of autoimmune diseases, cancers, and cardiovascular disease. Am J ClinNutr. 2004 Dec;80(6 Suppl):1678S-88S

8. RhodesLE, Webb, Fraser, Durkin. Recommended sunlight exposure produce sufficient but not optimal 25(OH)D at UK altitudes.J Invest Dermato1.2010 May;130(5):1411-8.Epub 2010 Jan2014.

9. Rucker D Allan JA, HNanley DA. Vitamin D Insufficiency in a population of healthy western Canadians. CMAJ. 2002JUN2011;166 (12):1517-24.

10. Holick MF.THE Vitamin D deficiency pandemic:a forgotten hormone important forhealth.Public Health Reviews2010;32:267-283.

11. Benner A Al aliM, Hofmann. Vitamin D deficiency in healthy children in a sunny country: associated factors. Int J Food science nutrition.2009;5:60-70.

12. Balasubramanian S, Ganesh R. Vitamin D deficiency in exclusively breast-fed infants. Indian $\mathrm{J}$ Med Res. 2008 Mar;127 (3):250-5. Review

13. Wayse V1, Yousafzai A, Mogale K, Filteau S. Association of subclinical vitamin D deficiency with severe acute lower respiratory infection in Indian children under 5 y. Eur J Clin Nutr. 2004 Apr;58 (4):563-7.

14. Roth DE1, Shah R, Black RE, Baqui AH. Vitamin $\mathrm{D}$ status and acute lower respiratory infection in early childhood in Sylhet, Bangladesh. Acta Paediatr. 2010 Mar;99 (3):389-93. doi: 10.1111/j.1651-2227.2009. 01594. x.Epub 2009 Nov 7. 


\section{Original Research Article}

15. Karatekin G1, Kaya A, Salihoğlu O, Balci H, Nuhoğlu A. Association of subclinical vitamin D deficiency in newborns with acute lower respiratory infection and their mothers. Eur J Clin Nutr. 2009 Apr;63(4):473-7. Epub 2007 Nov 21.

16. Nighathaider et.al. Frequency, causes and outcome of neonates with respiratory distress admitted to Neonatal Intensive Care Unit, National Institute of Child Health, Karachi.

17. Workinggroup of Australian and NewZealand Bone and Mineral society. Vitamin D and adult bone health.Med J Aust.2005;182:281-285.

18. Holick MF. Vitamin D deficiency, NEngl J MED2007;357:266-281. 20. Deluca HF.Overview of general physiological features and functions of vitamin D.Am J Clinical Nutrition.2004;80: supp1: 1689S1696s.
19. Gorham ED Garland CF etal. Vitamin D and prevention of colorectal cancer.JSteroid Biochemiacal Mol BlOLOGY.2005;97:179-194.

20. Khadilkar AV Vitamin D deficiency in Indian Adolescents. IAP2010;;47:755-756.

21. Sivakumar B.Nutrient requirements and RDI.vol3 Oxford\$BH, New Delhi.154-178.

22. Wagner CL,AAP breast feeding on nutrition. prevention of rickets and vitamin deficiency in infants,children.2008;122:1142-1152.

23. Ross AC Manson Abrams.dietary reference intake of calcium and Vitamin D.JClinicalEndocrinol Metab. m2011; 96:53-8Epub 2010 Nov 29.

24. Doets el Lambert. Current micronutrient recommendations in Europe.EurJNutrition .2008;47: $17-40$.

\section{How to cite this article?}

Ruhi A. ${ }^{1}$, Ananth T. A study of Vitamin-D and nutritional status in recurrent respiratory tract infections in children 1-5 years of age. Int J Pediatr Res. 2019;6(04):183-188. doi:10.17511/ijpr.2019.i04.06 